\title{
O traumático na psicanálise e psiquiatria: implicações ético-políticas
}

\section{| ' Stephan Malta Oliveira |}

Resumo: O objetivo do artigo consiste em articular o discurso psicanalítico e psiquiátrico sobre o trauma, extraindo as implicações ético-políticas desta articulação, além de promover um resgate da subjetividade pela psiquiatria. A justificativa é éticopragmática. A metodologia consiste na revisão não sistemática da literatura, mediante a seleção de textos que enfocam o traumático na psicanálise - a partir das categorias freudianas "neurose traumática", "compulsão à repetição", "pulsão de morte" e "passagem ao ato", além de textos de autores pós-freudianos e da literatura acerca dos testemunhos de catástrofes históricas, que situam o traumático na ordem do irrepresentável bem como a seleção de textos na área da psiquiatria, que tratam das categorias "estressores precoces" e "estresse pós-traumático", enfatizando a relação entre os estressores precoces e o desenvolvimento posterior de quadros psicopatológicos. Enfatiza-se também a susceptibilidade individual a determinados eventos traumáticos, bem como as bases neurobiológicas do TEPT. São extraídas importantes implicações éticopolíticas a partir da articulação proposta, que impactam no âmbito da clínica, levando a uma prática mais efetiva, e no âmbito político-social, com relação à elaboração de políticas públicas de saúde mental, que visam à prevenção de eventos traumatogênicos, bem como a oferta de serviços qualificados aos pacientes submetidos a vivências traumáticas.

> Palavras-chave: trauma psíquico; irrepresentável; estressores precoces; estresse pós-traumático.
1 Doutorado em Saúde Coletiva. Instituto de Medicina Social, Universidade do Estado do Rio de Janeiro-RJ, Brasil. Endereço eletrônico: stephanmoliveira@ gmail.com 


\section{Introdução}

No início e meados do século XX, a psicanálise constituía o paradigma dominante no campo da psiquiatria (SHORTER, 1997) e o discurso psicanalítico sobre o trauma, mediante categorias como "neurose traumática" e "compulsão à repetição", se fazia hegemônico. No entanto, na virada do século XX para o XXI, houve uma mudança paradigmática no campo da psiquiatria, marcada pela passagem de uma psiquiatria psicodinamicamente orientada - encontrada até o DSM-II - para uma psiquiatria objetivista e de cunho empirista, surgida com o advento do DSM-III, em 1980 (HAYES; HORWITZ, 2005). Pode-se dizer que a psiquiatria contemporânea caracteriza-se pelo que o historiador do campo, Edward Shorter, denomina "a segunda psiquiatria biológica", que surge com os recentes estudos em neurociências e biologia molecular, os avanços no domínio da psicofarmacologia e, principalmente, com a mudança paradigmática ocorrida com o DSM-III. A psiquiatria busca se tornar científica, situando seu saber no interior da racionalidade biomédica, herdeira da racionalidade científica. ${ }^{1} \mathrm{O}$ discurso dominante acerca do trauma se torna, então, aquele da psiquiatria biológica, que enfoca as bases neurobiológicas do fenômeno, a ocorrência de estressores precoces e a construção da categoria nosológica "transtorno do estresse pós-traumático"

Mais que considerar ambos os discursos como mutuamente excludentes, o presente artigo pretende mostrar que uma articulação entre ambos tende a ser mais eficaz do ponto de vista pragmático-ético-político, tanto com relação ao âmbito da clínica quanto com relação ao âmbito político-social. Além disso, busca-se promover um resgate da dimensão subjetiva pelo campo da psiquiatria.

A metodologia do artigo consiste numa revisão não sistemática da literatura através da seleção de textos psicanalíticos que enfocam a questão do trauma psíquico e textos na psiquiatria que enfocam as noções de estressores ambientais/ precoces e transtorno de estresse pós-traumático (TEPT). Na psicanálise, a seleção é voltada para trabalhos que privilegiam a noção do traumático segundo a ótica do irrepresentável. Considera-se como o traumático aparece na clínica contemporânea, enquanto comportamentos de passagens ao ato e o fator ambiental como possível agente traumatogênico. Discute-se ainda a questão do trauma nos testemunhos de catástrofes históricas, bem como a noção de afeto de angústia. São utilizados textos específicos de autores clássicos como Freud, Ferenczi, Winnicott, além de textos de autores contemporâneos pós-freudianos. 
No campo da psiquiatria, foram selecionados alguns artigos que tratam

das categorias "estresse precoce" e "transtorno do estresse pós-traumático", que apontam para a relação entre estressores precoces e o desencadeamento posterior de determinado transtorno mental. Além disso, foram selecionados artigos que tratam das bases neurobiológicas do TEPT. O método utilizado é o da investigação conceitual. ${ }^{3}$

O pragmatismo jamesiano, deweyano e putnamiano fundamentam o artigo, possibilitando a articulação entre campos que incidem sobre diferentes níveis de descrição: o campo psicanalítico incidindo sobre o nível subjetivo/intersubjetivo, e o campo psiquiátrico, sobre o nível biológico e ambiental. Duas categorias pragmatistas são utilizadas no sentido de embasar a articulação proposta: eficácia prática e relatividade conceitual.

De acordo com James (1907/1955) e Dewey (1929), a validade de uma teoria se dá segundo sua eficácia prática. As teorias devem ser compreendidas como ferramentas, que devem ser utilizadas para solucionar problemas e transformar nossas vidas e práticas para melhor. Relatividade conceitual, por sua vez, diz respeito ao fato de que duas afirmaçôes antagônicas podem ser ambas verdadeiras, sendo mais ou menos eficazes dependendo do contexto e do propósito (PUTNAM, 1999). As duas categorias conceituais utilizadas resultam num pluralismo: no caso deste artigo, interessa-nos o pluralismo epistêmico (múltiplas descrições para cada evento/fenômeno) e pluralismo clínico (múltiplas abordagens clínicas).

A articulação entre diferentes níveis descritivos se mostra pragmaticamente eficaz no campo da psiquiatria e saúde mental, uma vez que atende à complexidade do objeto de estudo da psiquiatria ${ }^{4}$ è complexidade da própria clínica psiquiátrica (ver OLIVEIRA, 2014).

\section{O traumático na psicanálise}

Freud, em seu texto de 1920, "Para além do princípio do prazer", reformula a noção defendida até então de que o princípio do prazer governa a vida psíquica. Ele, entretanto, não deixa de considerar a importância do princípio do prazer em alguns processos psíquicos, mas admite que nem todos os processos tendem ao prazer. $\mathrm{O}$ autor concebe o princípio do prazer como a busca de prazer pelo aparato psíquico e a evitação de qualquer forma de desprazer. Este princípio é 
o que caracteriza o processo primário. Trata-se de um modelo quantitativo, no qual o prazer é compreendido como uma diminuição do quantum de energia psíquica, e o desprazer, como um aumento desta energia, numa analogia com o sistema termodinâmico.

Em "Além do princípio do prazer", Freud (1920/2007) admite, no entanto, outro modo de funcionamento do aparelho psíquico não regido pelo princípio do prazer; funcionamento que leva, em última instância, ao desprazer. Tal operação é encontrada no que o autor denomina "compulsão à repetição", na qual o material "reprimido" é apenas repetido na relação transferencial e não recordado, e o resultado final é sempre uma experiência de desprazer. Sensações de desprazer retornam, então, através dos sonhos, da relação transferencial ou de atos que se repetem, numa tentativa de resolução.

Embora Freud (1920/2007) confira ênfase especial à ideia de representação mental, considerando que o trauma psíquico é caracterizado por representaçôes proibidas, as quais sofreram a ação da repressão e foram recalcadas, há indícios nos quais o autor aponta para uma vertente do traumático situado na ordem do irrepresentável. Ao tratar das neuroses traumáticas, por exemplo, Freud concebeas como resultado de eventos traumáticos, como "choques ferroviários ou outros acidentes", ou ainda, "choques de guerra", que levam a um excesso de excitação psíquica que ultrapassa as "barreiras de proteção" do sistema nervoso central, e consequentemente, sua capacidade de ligação, engendrando o trauma psíquico. Antes mesmo da construção desta categoria, Freud já havia, no início dos seus escritos, por volta do final do século XIX, realizado um esboço do que seria o traumático enquanto uma excitação pulsional não ligada; portanto, situado na ordem do irrepresentável, quando construiu inicialmente a categoria "neurose de angústia”, na qual a excitação - considerada à época, de origem sexual - por não possuir uma derivação psíquica - libido - transformava-se em angústia, e posteriormente a categoria "neuroses atuais", que compreendia a própria neurose de angústia, a neurastenia e a hipocondria (FERRAZ, 1997).

Semelhantemente à neurose traumática, a compulsão à repetição também se caracteriza por um excesso de energia livre circulando no aparelho psíquico, que busca a descarga motora direta, ou seja, sem a mediação do psiquismo, e culmina com uma sensação de desprazer. A diferença é que, no primeiro caso, o excesso de energia é de origem exógena, enquanto no segundo, de origem endógena. 
Outra elaboração freudiana presente na compulsão à repetição e que aponta para uma impossibilidade de representação no trauma psíquico é o conceito de pulsão de morte. De acordo com Campos (2011, p. 861), a pulsão de morte abre lugar ao irrepresentável na metapsicologia freudiana, ao nomear o "que resiste a todas as possibilidades de elaboração e ligação psíquica”. A pulsão de morte caracteriza o excesso pulsional presente na compulsão à repetição, que busca satisfação através da descarga motora direta nas chamadas "passagens ao ato". Esses comportamentos se encontram cada vez mais presentes na clínica contemporânea, traduzindo-se nas tentativas de suicídio, no uso abusivo de substâncias psicoativas e exposições frequentes a situações de risco, como práticas sexuais desprotegidas, além das automutilações, cada vez mais comuns na clínica, e das autoagressões.

O conceito de pulsão de morte merece destaque especial neste trabalho devido às complexas questôes que surgem com o dualismo pulsional formulado por Freud, mais especificamente, com relação à complexa imbricação que esta noção estabelece com as pulsões de vida. Figueiredo (1999) critica a simplificação e redução das noções de pulsão de vida e pulsão de morte à energia psíquica ligada e energia psíquica (ou excesso pulsional) não ligada, respectivamente. Ele mostra que, na verdade, há uma complexa imbricação entre as duas pulsões. Para isto, se apoia no texto freudiano "O ego e o id", de 1923, afirmando que "Eros persegue a meta de complicar a vida mediante a reunião, a síntese, da substância viva dispersa em partículas" e que "são as pulsões sexuais que, como necessidades pulsionais, detém a queda de nível (gerada pelas pulsões de morte) e introduzem novas tensōes (FIGUEIREDO, 1999, p. 39-40). ${ }^{5}$

Ou seja, as pulsões de vida geram energia não ligada ao mesmo tempo em que ligam e reúnem elementos. Bissoli (2004), em sua resenha sobre a obra de Figueiredo, "Palavras cruzadas entre Freud e Ferenczi", afirma que Eros - as pulsões de vida - busca simultaneamente o incremento e a redução de tensões. O autor menciona uma passagem de Ferenczi, em Thalassa, na qual o psicanalista húngaro refere que a sexualidade brinca com o perigo. Não é difícil imaginar que, se a obtenção do prazer corresponde à redução da energia psíquica, à descarga pulsional, logo, o próprio princípio do prazer necessita do aumento da tensão psíquica para sua posterior descarga. Complexificando ainda mais a questão, o aumento da tensão psíquica pode ser reconhecido como prazeroso em algumas situaçóes, como no ato 
sexual, como o próprio Freud admitiu, assim como em outras condições, como num jogo esportivo, na luta por causas ideológicas, dentre outras.

Bissoli (2004) interpreta que Figueiredo estabelece uma crítica à terminologia "pulsão de morte”, sem discordar, entretanto, do sentido da expressão, reconhecendo-a como o "mais pulsional das pulsões", como um movimento em direção "ao estado anterior das coisas", à "existência inorgânica”. Bissoli afirma que parece haver em Figueiredo um monismo pulsional governado por Eros, tal qual em Winnicott, o qual admite a existência apenas das pulsões de vida, atrelando a agressividade a Eros, como uma força constitutiva da criatividade.

A partir das questôes mencionadas, apoio-me nas considerações de Prata (2000) sobre a fusão pulsional - relacionada a processos criativos, de ruptura e a desfusão pulsional - relacionada a processos mortificadores - e interpreto/ formulo que, nas pulsões de vida, há um intrincamento entre a energia ligada e um excesso pulsional "passível de elaboração, de ligação”. Este mesmo excesso é que possibilita a emergência de processos criativos, que rompe a estabilidade, proporcionada pela energia ligada, até que haja um novo restabelecimento da mesma. É a "força motora" da vida. O escoamento deste excesso pode se dar por meio de atividades físicas e/ou sublimadas (como atividades intelectuais ou artísticas), da imaginação, fantasia ou sonhos. Por outro lado, o excesso pulsional "que resiste a qualquer tentativa de ligação" e que se encontra, portanto, desintrincado da energia ligada, é que constitui a pulsão de morte. Nesta concepção, a pulsão de morte aparece apenas nos casos de desfusão pulsional.

Diferentemente de Freud, cuja ênfase recaía sobre o mundo intrapsíquico, Ferenczi e Winnicott privilegiam o ambiente como possível fator causador dos traumas psíquicos. Winnicott (1965[2013]) desenvolve a noção de "ambiente suficientemente bom", apontando a importância deste para o desenvolvimento saudável do sujeito, marcado pela maturação emocional, ou seja, pela consolidação dos processos de integração - senso de continuidade do eu no espaço e tempo -, de personalização - se refere ao alojamento da psique no soma, ao desenvolvimento da unidade psicossoma -, e realização - emergência de um senso do real (WINNICOTT, 1965[2013]).

Uma das noções winnicottianas que representam bem a ênfase que o autor confere à dimensão ambiental é a de manejo (management). Um aspecto importante do manejo se refere à identificação da mãe com o bebê, no sentido de reconhecer 
suas necessidades físicas e emocionais. Outro aspecto é o do holding, que diz respeito a todos os cuidados ofertados à criança, representados por experiências sustentadoras (OLIVEIRA, 2012). O holding consiste em cuidados contínuos e previsíveis, suficientemente bons, que possibilitam ao bebê desenvolver um sentido de si mesmo e a identidade pessoal (LEJARRAGA, 2008). A partir do holding é que se dá o manuseio físico do bebê, o modo como a mãe o toca e o acolhe (handling). É justamente este manejo que a mãe oferta à criança análogo àquele que o terapeuta deve ofertar a seu paciente, segundo a clínica winnicottiana - que possibilita a consolidação dos processos maturacionais do sujeito (LEJARRAGA, 2008; OLIVEIRA, 2012).

O desenvolvimento saudável em Winnicott se caracteriza pela emergência do senso de confiança, do gesto espontâneo e do verdadeiro self, que caracterizam o "viver criativo", no qual o sujeito sente que "a vida é digna de ser vivida" (WINNICOTT, 1975, p. 95). Por outro lado, para o autor, "falhas" nesse ambiente suficientemente bom estariam relacionadas diretamente ao engendramento do trauma psíquico. Deste modo, o processo de personalização e integração do eu, que se desenvolve de maneira apropriada num "ambiente facilitador", tenderá à fragmentação. $\mathrm{O}$ sujeito adota uma postura defensiva diante desta vivência, constituindo o falso self, que "bloqueia" o gesto espontâneo e a criatividade, adotando uma posição de submissão diante da vida, onde sente que "não vale a pena viver a vida” (WINNICOTT, 1975, p. 95). Há uma fragmentação do eu e uma clivagem da unidade psicossoma.

Lejarraga (2008) afirma que o termo winnicottiano "agonias impensáveis" apresenta uma estreita relação com os conceitos de falso-selfe de trauma psíquico, sendo todas estas noções indissociáveis de sua teoria do amadurecimento emocional. Segundo a autora, o engendramento do trauma psíquico em Winnicott diz respeito, sobretudo, às pequenas e constantes falhas do ambiente em atender às necessidades do bebê. Este, então, experiencia uma ameaça de aniquilamento e de ruptura da continuidade do ser. Essa ruptura é vivenciada como uma agonia impensável, que não pode ser pensada nem ao menos representada. Em resposta a esta ameaça de aniquilamento, o bebê reage e constitui defensivamente o que Winnicott denomina "falso-self", em proteção ao "verdadeiro-self".

Outro importante autor psicanalítico a se debruçar sobre a questão do trauma foi o húngaro Sandor Ferenczi (1933[2011]), que também confere especial 
importância ao ambiente externo como possível agente traumatogênico. Dentre os eventos ambientais com potencial para engendrar um trauma psíquico, ele menciona o abuso sexual, a punição passional e o "terrorismo de sofrimento", no qual a criança "carrega sobre seus ombros o fardo de todos os membros da família” (FERENCZI, 2011, p. 120).

O trauma psíquico, para Ferenczi, caracteriza-se por um estado de passividade e pela suspensão de todo tipo de percepção, resultantes de um choque inesperado, não preparado e esmagador. As impressões sensíveis traumáticas não subsistem a nenhum traço mnêmico e, consequentemente, não são acessíveis às tentativas de rememoração. Knobloch (1998), ao fazer uma releitura da obra ferencziana, estabelece uma distinção entre marcas e traços. Nas primeiras, as impressões sensíveis não se inscrevem no registro mnêmico, e sim no corpo, não sendo, portanto, inscritas na rede representacional, constituindo as chamadas "marcas corporais”. É a dimensão do irrepresentável em Ferenczi. Por outro lado, os traços mnêmicos são constituídos por impressões sensíveis que se inscrevem no sistema de memórias e, conjuntamente com outros traços mnêmicos, constituem uma representação.

Knobloch (1998) mostra que, diferentemente de Freud, Ferenczi defendia a possibilidade de se analisar os casos "não analisáveis", como os pacientes psicóticos e os "estados-limite" ou borderline. Para isto, propunha uma modificação da técnica analítica, uma "elasticidade da técnica", para acessar o material correspondente à experiência traumática. Ferenczi propôs, para tal, que se adotasse a técnica do "sentir com", na qual o analista devia buscar obter um envolvimento empático com o paciente e "sentir o que ele estava sentindo", bem como a técnica de "relaxamento", na qual o analista deveria possibilitar que o paciente atingisse um estado tal de relaxamento que constituíria, de fato, um estado regressivo (FERENCZI, 2011; KUPERMANN, 2010). Segundo Kupermann (2010), as inovações técnicas ferenczianas permitiam que se obtivesse uma melhora clínica, por resultarem numa forma de elaboração psíquica das excitaçôes pulsionais relacionadas às vivências traumáticas - que se passava pela via sensível, corporal, através do que o psicanalista húngaro denominava "neocatarse", que correspondia a descargas emocionais intensas que ocorriam durante o tratamento analítico com a técnica do relaxamento.

O trauma psíquico como impossibilidade de representação se faz presente também na literatura sobre os testemunhos de catástrofes históricas, como relatos 
a partir de experiências em campos de concentração ou genocídios, nos quais há uma impossibilidade de se narrar o trauma, uma impossibilidade de simbolização dessas vivências (SELIGMANN-SILVA, 2008). A narrativa testemunhal dessas experiências traumáticas, situadas do lado de fora do campo simbólico, permite que se mantenha a memória do trauma, que o acontecimento não caia no esquecimento. Isto parece levar a um tipo de elaboração da experiência, de distanciamento, que permite ao "sobrevivente" passar da "sobrevida" à "vida" (SELIGMANN-SILVA, 2008; SCHWEIDSON, 2003). Schweidson (2003, p. 34), ao comentar sobre a obra de um dos mais conhecidos sobreviventes dos campos nazistas, Primo Levi, refere que seu trabalho "permanece afirmando sua opção de escrever contra o esquecimento, contra o inumano e sua repetição, no dever da memória, que o faz maior que a morte do simbólico que os campos tentavam instaurar”.

O traumático também aparece em sua dimensão irrepresentável na relação com o afeto de angústia. De acordo com Besset (2001, p. 138), a primeira conceituação freudiana do termo a "concebia como uma tensão, de caráter sexual, que não conseguia ligar-se psiquicamente”. Além disso, o conceito de angústia caracteriza uma neurose específica, do mesmo nome - neurose de angústia na qual o afeto não admite "nenhuma derivação psíquica", não transformandose, portanto, em libido (FREUD, 1895[1988], apud BESSET, 2001, p. 138). Segundo a autora, para Lacan, trata-se de uma das definiçôes do Real, daquilo que não pode ser apreendido pelo simbólico, de algo que se situa no domínio corporal. Vital Brazil (2003) afirma que a confrontação com o Real pode expor o sujeito à angústia sem nome e que este afeto, concebido como um afeto sem objeto nas formulações freudianas, é paradigmático de todo sofrimento psíquico e aponta necessariamente para um efeito de de-simbolização.

Há, como pôde ser observado nos textos relacionados à noção do trauma na psicanálise, uma tendência a uma subjetividade corporificada, ancorada no corpo, que não se caracteriza apenas por representações mentais, mas se inscreve no registro corporal. Esta tendência pode ser observada, sobretudo, nos autores pósfreudianos e aponta para a superação da tradicional dicotomia cartesiana corpo/ mente. Outra tendência encontrada nos textos pós-freudianos, sobretudo nos autores contemporâneos, é a valorização de uma descrição qualitativa do trauma psíquico em detrimento de uma descrição quantitativa, como proposta inicialmente por Freud. A analogia com o sistema termodinâmico deve ser compreendida, à luz 
do debate atual, mais como uma metáfora e menos como descriçõos passíveis de mensuração. Além disso, a subjetividade encontrada em autores como Winnicott e Ferenczi deve sempre ser compreendida como situada num contexto específico (embedded), sendo, portanto, desde sempre intersubjetividade.

Um dos caminhos apontados pela psicanálise como possibilidade de superação das vivências traumáticas e que pode ter importantes implicações ético-políticas se apoia na noção de elaboração psíquica do trauma. De acordo com Ferraz (1997), ao citar Laplanche e Pontalis (1967), elaboração psíquica diz respeito ao trabalho (laborar) do aparelho psíquico para "dominar", para dar conta das excitações pulsionais, integrando-as às cadeias associativas e produzindo uma sensação de apaziguamento. A elaboração pode ser implícita - pela via sensível - ou explícita - pela via simbólica. Além disto, o terapeuta/médico pode e deve atuar, através da técnica do "sentir com" e de interações emocionalmente significativas, como um agente de psra-excitação.

\section{O traumático na psiquiatria}

No campo da psiquiatria contemporânea, a ideia do traumático ou experiência traumática abordada extensivamente pela psicanálise, emerge sob a forma de conceitos relacionados a eventos estressores, como "estresse precoce", "estressores ambientais", além da categoria "transtorno do estresse pós-traumático” (TEPT). Estes eventos estressores podem levar, em indivíduos susceptíveis, ao aparecimento de determinados quadros psicopatológicos. Nota-se que há uma valorização do ambiente como potencialmente traumático.

Juruena et al. (2007) defendem a adoção de um novo paradigma no campo da psiquiatria, com enfoque interdisciplinar. Os autores afirmam que, atualmente, é amplamente aceito que o estresse psicológico pode alterar a homeostase interna de um indivíduo e que enfermidades podem advir de um estresse, seja ele agudo ou crônico. Os autores mostram ainda que o ambiente social e físico tem enorme impacto sobre o funcionamento fisiológico, alterando o funcionamento cerebral e neurobiológico e influenciando o processo de adaptação. Um dos principais mecanismos responsáveis pelas alterações neurobiológicas que resultam da experiência são os mecanismos epigenéticos, os quais atuam sobre mecanismos de regulação da expressão gênica, ativando ou silenciando determinados genes ao longo do desenvolvimento (JAENISH; 
BIRD, 2003). Devido à complexidade desta questão, advoga-se a necessidade de um enfoque interdisciplinar, integrando diversos campos do conhecimento, como a Física, a Fisiologia, a Psicologia, a Filosofia, a Antropologia Cultural, a Neurobiologia, dentre outros (JURUENA et al., 2007).

O estresse constitui uma reação normal e esperada do organismo frente a um evento estressor ou de ameaça. Valente et al. (2008), por exemplo, afirmam que o estresse é um estado de excitação em resposta a um estressor, que se caracteriza por mudanças biopsicológicas, as quais podem trazer tanto consequências positivas quanto negativas para a adaptação. Do ponto de vista evolucionista, as três principais respostas do organismo frente a uma ameaça ou perigo são as reações de luta, fuga ou imobilidade/congelamento. Um dos aspectos positivos do estresse é que ele resulta na ativação do eixo hipotálamo-pituitária-adrenal (HPA) que, por sua vez, leva ao aumento da glicogênese e da entrada de glicose nas células, o que é extremamente útil em situações nas quais o organismo necessita de quantidade maior de energia. Entretanto, a permanência do evento estressor, bem como da resposta a este, de forma crônica, pode ter como consequência um quadro patológico (VALENTE et al., 2008).

Mello et al. (2007) realizaram estudo de revisão não sistemática da literatura procurando estabelecer uma relação entre estressores precoces, alteração do eixo HPA e depressão. Os autores relatam que diversos trabalhos foram publicados apontando a relação entre psicopatologia em adultos e adversidades vividas precocemente, como "perda de genitores na infância, cuidado parental inadequado, divórcio, educação 'sem afeto' ou disfuncional por parte dos pais, abuso físico e sexual, e outros traumas ocorridos na infância” (MELLO et al., 2007, p. S16). Há evidências consistentes de que a experienciação de estressores no início da vida está associada a um risco maior de desenvolvimento de quadros de transtornos de humor, transtornos de ansiedade e transtornos de personalidade na vida adulta (MELLO et al., 2007).

Um dos mecanismos que parecem mediar a relação entre os estressores precoces e a depressão é a alteração do funcionamento do eixo HPA. Reconhecese que a hipercortisolemia está associada à depressão, mas nem todos os pacientes com depressão apresentam hipercortisolemia. Estudos comparando indivíduos com depressão que apresentam disfunção do eixo HPA e indivíduos deprimidos sem esta disfunção mostram que os pacientes do primeiro grupo foram significativamente mais submetidos a estressores precoces (MELLO et al., 2009). 
Mello et al. (2007) afirmam que, como o eixo HPA é ativado em resposta a estressores, eventos estressantes precoces podem ter papel etiológico significativo nas anormalidades do eixo HPA. Estudo realizado por Mello et al. (2009) encontrou associação positiva entre disfunções do eixo HPA e maus-tratos na infância. Os autores afirmam que, embora as respostas agudas do eixo HPA sejam geralmente adaptativas, as respostas excessivas em virtude de um estresse crônico podem resultar em efeitos deletérios, fazendo com que alguns indivíduos submetidos a estressores precoces tenham reação fisiológica e comportamental exagerada frente aos estressores da vida diária, na vida adulta. De acordo com Mello et al. (2009), a hiperatividade do eixo HPA, caracterizada pela liberação excessiva de glicocorticoides, está relacionada a uma expressão diminuída do BDNF (brain-derived neurothrophic factor - fator neurotrófico derivado do cérebro) e, consequentemente, a uma redução da arborização dendrítica, da neurogênese e neuroplasticidade.

A relação entre a disfunção do eixo HPA e determinados quadros psicopatológicos parece ser ambígua, havendo uma hiperatividade em alguns casos e uma hipoatividade em outros. Em estudo realizado por Heim et al. (apud MELLO et al., 2009), os resultados mostraram que mulheres com histórico de abuso precoce, com ou sem depressão maior atual, apresentaram respostas aumentadas do hormônio adrenocorticotrófico (ACTH) ao estresse em comparação com controles. Por outro lado, mulheres deprimidas sem histórico de abuso precoce demonstraram respostas neuroendócrinas normais quando comparadas aos controles. No mesmo estudo, homens abusados apresentaram respostas de cortisol aumentadas quando comparados a homens não abusados, independentemente de terem depressão maior ou não. Além disso, a resposta aumentada ao cortisol foi associada à exposição a abuso físico e sexual e relacionada com a gravidade do abuso (MELLO et al., 2009).

Resultados similares foram encontrados em mulheres com transtorno de personalidade borderline. No entanto, em pacientes com TEPT e em mulheres com histórico de estresse precoce e TEPT, foram encontrados hipocortisolismo basal e a hipersupressão do cortisol após baixas doses de dexametasona, sugerindo uma disfunção do controle de feedback do eixo HPA (MELLO et al., 2009). Se, por um lado, estudos mostram que filhotes de ratos que receberam melhores cuidados maternos precoces desenvolvem maior capacidade de reação comportamental e 
biológica frente ao estresse, por outro, a redução de cortisol materno durante a gestação, como observado em gestantes que apresentaram TEPT em resposta aos ataques de 11 de setembro de 2001, pode provocar alteração comportamental nos recém-nascidos, levando a um aumento do desconforto dos bebês em resposta a estímulos novos (VALENTE et al., 2008).

A noção do traumático começou a se fazer presente de forma mais contundente na psiquiatria a partir da construção de uma categoria nosológica específica: o transtorno do estresse pós-traumático (TEPT), o qual privilegia a ocorrência de eventos traumáticos como possíveis causadores de uma perturbação mental. O TEPT apareceu pela primeira vez enquanto categoria nosológica oficial com o advento do DSM-III, em 1980 (FASSIN; RECHTMAN, 2009). Fassin e Retchman afirmam que a construção da categoria foi fruto de intensas e complexas negociações que envolveram a participação de diversos atores, não só pertencentes ao campo da Saúde Mental, mas a outros segmentos da sociedade. Dentre estes, os principais foram o Movimento Feminista dos anos 60 e os veteranos de Guerra do Vietnam. O Movimento Feminista defendeu a inclusão da categoria como uma maneira de lutar contra a violência contra as mulheres e o abuso infantil. Os veteranos da Guerra do Vietnam buscavam um reconhecimento público para sua condição de sofrimento, bem como a obtenção de ressarcimentos financeiros. Como afirma Summerfield (2001), a inclusão do TEPT no DSM-III marcou uma mudança na representação social dos veteranos de guerra, que deixaram de ser vistos como vilóes para serem vistos como "vítimas". Além disso, passaram a receber benefícios do Estado, sendo amparados pela legislação norte-americana.

De acordo com Fassin e Rechtman (2009), a emergência do TEPT representa um momento de mudança paradigmática no que se refere a compreensão e explicação do trauma. $\mathrm{O}$ discurso médico-psiquiátrico de cunho biologicista mas que não deixa de enfatizar a complexa interação entre indivíduo e meio - se torna dominante frente ao declínio da psicanálise, em geral, e do discurso psicanalítico sobre o trauma, mais especificamente. Segundo os autores, o TEPT, embora apresente inúmeras semelhanças em sua descrição com a categoria "neurose traumática", não faz nenhuma referência a "uma personalidade frágil" ou a possíveis "ganhos secundários inconscientes", mostrando que indivíduos "normais" podem ter reaçôes "normais" frente a situaçōes "anormais e inumanas". 
O TEPT caracteriza-se, de acordo com o DSM-IV-TR (2002), pelo surgimento de sintomas específicos após a exposição a um evento traumático, os quais compõem a seguinte tríade de dimensões psicopatológicas: 1) revivescência do trauma; 2) esquiva a estímulos que relembrem o evento traumático e distanciamento afetivo; e 3) hiperestimulação autonômica. O DSM-IV ampliou a categoria do TEPT, passando a incluir outros eventos traumáticos como necessários para o diagnóstico, como acidentes automobilísticos, transtornos clínicos agudos e crônicos, estresse relacionado ao trabalho e desastres ocasionados pelo homem, além dos já incluídos no DSM-III - eventos traumáticos graves, como torturas, estupros, experiências de combate e desastres naturais (MAURAT; FIGUEIRA, 2001).

Esta categoria nosológica aponta para a complexa interação entre fatores genéticos e fatores ambientais na etiopatogênese de determinado transtorno mental. No discurso psiquiátrico contemporâneo sobre o trauma, considerase que há uma complexa interação entre os fatores constitucionais e os eventos traumáticos. A susceptibilidade individual ao trauma deve ser levada em conta, uma vez que nem todos os eventos traumáticos ou estressores ambientais resultarão em trauma psíquico ou psicopatologia. Por isso mesmo, uma nomenclatura preferível seria "eventos potencialmente traumáticos", em vez de "eventos traumáticos". Determinado evento estressor pode ser traumático para um indivíduo e não ser para outro, e ainda ter diferentes impactos sobre um mesmo indivíduo ao longo de sua vida, dependendo da fase de desenvolvimento em que se encontra. Em indivíduos vulneráveis, eventos estressores de menor impacto podem resultar numa vivência traumática ou desencadear o TEPT, enquanto em indivíduos resilientes, estressores de grande impacto podem não ter efeitos traumatogênicos.

Valente et al. (2008) descrevem estudos que apontam a presença de uma predisposição genética no TEPT. Estudos com gêmeos, por exemplo, mostram que a concordância da presença de TEPT entre gêmeos submetidos a um trauma é maior entre os monozigóticos quando comparados aos dizigóticos.

Com relação à neurobiologia do transtorno, alguns sistemas neuronais parecem estar perturbados, dentre eles o sistema serotoninérgico, o sistema dopaminérgico e o sistema de receptores glicocorticoides. Com relação ao sistema serotoninérgico, sabe-se que o alelo curto (s) no gene 5HTTLPR (um polimorfismo no gene transportador de serotonina) está associado com uma menor eficiência de transcrição, comparado ao alelo longo (l). Isto poderia levar a menor eficácia na 
moderação da resposta ao estresse (VALENTE et al., 2008). Murphy et al. (apud

Valente et. al, 2008) encontraram que ratos que têm esse alelo curto apresentam resposta exagerada do eixo H-P-A ao estresse. Em outro estudo, Bennett et al. (apud Valente et al., 2008) demonstraram que macacos rhesus, portadores do alelo $s$, têm uma função serotoninérgica diminuída quando comparados aos macacos que possuem o mesmo alelo, mas criados em ambientes não estressantes.

Outro sistema neuronal envolvido no TEPT é o de receptores glicocorticoides. Valente et al. (2008) afirmam que uma das características dos pacientes com TEPT é uma sensibilidade aumentada aos receptores glicocorticoides. Os receptores corticosteroides (glicocorticoides - GR; e mineralocorticoides - MR) funcionam como reguladores da transcrição gênica, sendo seus efeitos sobre o comportamento fruto de uma expressão gênica alterada. Veenema et al. (apud VALENTE et al., 2008), em estudo realizado com ratos, constataram que animais que não apresentavam comportamento agressivo diante de uma ameaça mostravam diminuição na expressão do RNAm dos receptores mineralocorticoides. Por outro lado, situações ambientais estressoras provocavam mudanças súbitas na expressão do RNAm de ambos os receptores, GR e MR. Os autores concluíram que a hiperatividade do cortisol induzida pelo estresse estava presente apenas nos ratos não agressivos, ou seja, naqueles que apresentavam reações de esquiva ou imobilidade, mas não naqueles que apresentavam reações de "luta" (VALENTE et al., 2008).

Os achados mostrados anteriormente retratam a complexa articulação entre o indivíduo e o evento traumatogênico com relação ao desencadeamento do TEPT. Portanto, segundo a ótica do discurso psiquiátrico contemporâneo, os eventos traumáticos constituem uma condição necessária, mas não suficiente para o TEPT, uma vez que fatores como a predisposição genética ao transtorno estão presentes.

\section{Consideraçōes finais}

Algumas importantes implicações ético-políticas podem ser extraídas a partir do presente artigo, tanto com relação ao âmbito da clínica, quanto com relação ao âmbito político-social. No âmbito da clínica, a articulação entre os discursos psicanalítico e psiquiátrico sobre o trauma tende a levar a maior eficácia prática. A apropriação ou reapropriação, pela psiquiatria, do discurso psicanalítico acerca do trauma tende a enriquecer a práxis psiquiátrica em virtude da revalorização da dimensão subjetiva da experiência, negligenciada na psiquiatria mainstream. 
A contribuição da psicanálise à clínica do trauma se dá, sobretudo, pela ênfase e valorização da elaboração psíquica, que pode se dar pela via sensível, atividades físicas, pela via imaginativa, exploração de fantasias e sonhos, por meio de atividades sublimadas, como atividades artísticas, bem como por processos de simbolização e co-construção de significados acerca das vivências traumáticas, que possibilitam o "domínio" das excitações pulsionais, resultando em transformaçōes de afetos irrepresentáveis e intoleráveis em afetos mais manejáveis e toleráveis. A psiquiatria, por outro lado, contribui pela ênfase tanto à dimensão biológica quanto à dimensão ambiental do trauma. $\mathrm{Na}$ dimensão biológica, a terapêutica farmacológica vem se tornando cada vez mais eficaz, por meio de fármacos que diminuem os sintomas do TEPT, como os ISRSs e os benzodiazepínicos, reduzindo o sofrimento e possibilitando a superação da vivência traumática. Um dos alvos terapêuticos de estudos recentes tem sido a investigação de psicofármacos que diminuem a atividade do eixo H-P-A, reduzindo, desta maneira, a reatividade emocional do indivíduo aos estressores ambientais. As implicaçóes do discurso psiquiátrico sobre o trauma que incide sobre o nível ambiental se confundem com as implicações da discussão apresentada para o âmbito político-social.

No âmbito político-social, a articulação entre a psiquiatria e a psicologia já vem sendo realizada pelas diversas organizaçôes internacionais que prestam apoio a vítimas de catástrofes ou guerras, como o Médico Sem Fronteiras e o Médicos do Mundo. Como mostram Fassin e Rechtman, a partir dos anos 90, aproximadamente, essas organizaçóes incluíram em seu projeto um programa específico de saúde mental, que conta tanto com psiquiatras quanto profissionais da psicologia e da assistência social. As estratégias são voltadas para as vítimas de catástrofes, enfatizando-se a dimensão testemunhal das intervenções.

Com relação à elaboração de políticas públicas de saúde mental, diversas estratégias preventivas devem ser pensadas no sentido de combater a ocorrência de eventos traumatogênicos, como a violência urbana, acidentes automobilísticos, desastres ocasionados pelo homem e mesmo desastres naturais que podem ser impedidos pela ação humana, além de estratégias que combatam a ocorrência de estressores precoces (como o abuso físico, sexual e psicológico) e a negligência (que combatam a violência doméstica). 
Deve-se elaborar também políticas públicas que possibilitem a formação de recursos humanos especializados e serviços de saúde mental qualificados, voltados tanto para intervenções sobre a dimensão subjetiva do paciente - utilizando, portanto, o background teórico psicanalítico, mediante a ênfase na elaboração psíquica -, quanto para intervenções sobre a dimensão biológica, através da utilização do background psiquiátrico-neurobiológico acerca do trauma e da administração de psicofármacos eficazes - e sobre a dimensão ambiental, mediante reordenações do micro e macrocontexto sócio-cultural no qual o paciente se insere.

Conclui-se o artigo com a afirmação de que uma articulação entre o discurso psicanalítico e o discurso psiquiátrico sobre o trauma é pragmaticamente eficaz no âmbito ético-político, resultando numa prática clínica e político-social mais efetiva. Novos estudos devem ser realizados, entretanto, com o intuito de corroborar a importância e a necessidade de articulação entre discursos que incidem sobre diferentes níveis e dimensōes da experiência humana.

\section{Referências}

BESSET, V.L. A clínica da angústia: um lugar para o sujeito. Temas em Psicologia da SBP, v. 9, n. 2, p. 137-143, 2001.

BISSOLI, S.S.P. Resenha do livro Palavras Cruzadas entre Freud e Ferenczi (1999), de Luis Cláudio Figeuiredo. Revista Científica Eletrônica de Psicologia, ano II, n. 3, s/p, 2004. Disponível em: <http://faef.revista.inf.br/imagens_arquivos/arquivos_destaque/6YsC4tly w2v5qmW_2013-4-30-14-54-53.pdf>

CAMPOS, E.B.V. Limites da representação na metapsicologia freudiana. Psicologia USP. São Paulo, v. 22, n. 4, p. 851-877, 2011.

DEWEY, J. Experience and nature. London: George Allen \& Unwin, 1929.

FASSIN D.; RECHTMAN, R. The empire of trauma: an inquiry into the condition of victmhood. Cambridge: Princeton University Press, 2009.

FERENCZI, S. Confusão de língua entre os adultos e a criança. In: Obras Completas. Psicanálise IV. São Paulo: WMF Martins Fontes, 2011 [1933]. p. 111-121. . Reflexões sobre o trauma. In: . Obras Completas. Psicanálise IV. São Paulo:

WMF Martins Fontes, 2011, p. 125-135.

FERRAZ, F.C. Das neuroses atuais à psicossomática. In: FERRAZ, F.C.; VOLICH, R.M. (Orgs.). Psicossoma I-Psicanálise e Psicossomática. São Paulo: Casa do Psicólogo, 1997. p. 25 -40. 
FERRY, L. Apprendre à viure. Traité de philosophie à l'usage des jeunes générations. Paris: PLON, 2006.

FERRY, L. O Homem-Deus ou o sentido da vida. Rio de Janeiro: DIFEL, 2007.

FIGUEIREDO, L.C. Palavras cruzadas entre Freud e Ferenczi. São Paulo: Escuta, 1999.

FREUD, S. As pulsões e suas vicissitudes. Edição Standart. das Obras Completas (ESB). Rio de Janeiro: Imago, 1996[1915].

FREUD S. Más allá del principio de placer. Psicologia de las masas y análisis del yo y otras obras. 1920-1922. In: Obras completas, v. XVIII. Buenos Aires: Amorrortu, 2007 [1920].

HORWITZ, A.V. Creating mental illness. Chicago: The University of Chicago Press, 2002.

JAENISCH, R.; BIRD, A. Epigenetic regulation of gene expression: how the genome integrates intrinsic and environmental signals. Nature Genetic Supplement, v. 33, p. 245-254, 2003.

JAMES, W. Pragmatism and four essays from the Meaning of Truth. New York: Meridian Books, 1955[1907].

JURUENA, M.F. et al. Um paradigma para entender e tratar as doenças psiquiátricas. Revista Brasileira de Psiquiatria, v. 29, supl. I, p. S1-2, 2007.

KNOBLOCH, F. O tempo do traumático. São Paulo: EDUC, 1998.

KUPERMANN, D. A via sensível da elaboração psíquica. Caminhos da clínica psicanalítica. Cad. Psicanál. - CPRJ, v. 32, n. 23, p. 31-45, 2010.

LEJARRAGA, A.L. Clínica do trauma em Ferenczi e Winnicott. Natureza humana, v. 10, n. 2, p. 115-148, 2008.

LIMA, B. S. "Do amor em tempos de cólera": agressividade, subjetividade e cultura. Tese. 289f. (Doutorado em Psicologia) - Programa de Pós-Graduação em Psicologia Clínica. Pontifícia Universidade Católica do Rio de Janeiro, Rio de Janeiro, 2007.

MARTINS, A. Filosofia e saúde: métodos genealógico e filosófico-conceitual. Cadernos de Saúde Pública. Rio de Janeiro, v. 20, n. 4, p. 950-958, 2004.

MAURAT, A.M.; FIGUEIRA, I. Tratamento farmacológico do transtorno de estresse póstraumático. Revista de Psiquiatria Clínica, v. 28, n. 4, p. 191-196, 2001.

MELLO, A.F. et al. Depressão e estresse precoce: existe um endofenótipo? Revista Brasileira de Psiquiatria, v. 29, supl. I, p. S13-18, 2007.

MELLO, M.F. et al. Maus-tratos na infância e psicopatologia no adulto: caminhos para a disfunção do eixo hipotálamo-pituitária-adrenal. Revista Brasileira de Psiquiatria, v. 31, supl. II, p. S41-48, 2009.

OLIVEIRA, F.G. Do amadurecimento ao encontro analítico: um percurso clínico pela obra de Winnicott. Dissertação. 150f. (Mestrado em Psicologia) - Programa de Pós-Graduação em Psicologia Clínica. Pontifícia Universidade Católica do Rio de Janeiro. Rio de Janeiro, 2012. 
OLIVEIRA, S.M. Uma perspectiva multinivel e plural em psiquiatria: a esquizofrenia como exemplar. Tese. 196 f. (Doutorado em Saúde Coletiva) - Programa de Pós-Graduação em Saúde Coletiva. Instituto de Medicina Social, Universidade do Estado do Rio de Janeiro, Rio de Janeiro, 2014.

PRATA, M.R. Pulsão de morte: mortificação ou combate? Ágora, v. III, n. 1, p. 115-135, 2000. PUTNAM, H. O realismo de rosto humano. Lisboa: Instituto Piaget, 1999.

ROTELLI, F. Desinstitucionalização: uma outra via. In: NICÁCIO, M.F. (Org.). Desinstitucionalização. São Paulo: Hucitec, 1990. p. 17-59.

SCHWEIDSON, E. Inscrito como testemunha: Primo Levi e a escrita do trauma. Tempo Psicanalitico, v. 35, p. 23-36, 2003.

SELIGMANN-SILVA, M. Narrar o trauma: a questão dos testemunhos de catástrofes históricas. Psicologia Clínica - Psicanálise: teoria e clínica. Rio de Janeiro, v. 20, n. 1, p. 65-82, 2008.

SHORTER, E. A History of Psychiatry: from the era of the asylum to the age of Prozac. New Jersey: John Wiley \& Sons, 1997.

SUMMERFIELD, D. The invention of post-traumatic stress disorder and the social usefulness of a psychiatry category. British Medical Journal, v. 322, p. 95-98, 2001.

TESSER, C.; LUZ, T.M. Racionalidades Médicas e Integralidade. Ciência e Saúde Coletiva. Rio de Janeiro, v. 13, n. 1, p. 195-206, 2008.

VALENTE, N.L.M. et al. Evolucionismo e genética do transtorno de estresse póstraumático. Revista de Psiquiatria RS, v. 30, supl. 1, p. , 2008.

VITAL BRAZIL, H. O reconhecimento simbólico, a interpelação e o confronto com o real. Tempo Psicanalítico, v. 35, p. 57-73, 2003.

WILLIAMS, S.J.; CALNAN, M. The "limits" of medicalization? Modern medicine and the lay populace in "late" modernity. Soc. Sci. Med., v. 42, n. 12, p. 1609-1620, 1996.

WINNICOTT, D.W. A familia e o desenvolvimento individual. 4a. ed. 2a. tiragem. São Paulo: Martins Fontes, 2013 [1965]. . O brincar e a realidade. Rio de Janeiro: Imago, 1975.

\section{Notas}

${ }^{1}$ De acordo com Tesser e Luz (2008, p. 196), "racionalidade médica é um conjunto integrado e estruturado de práticas e saberes composto de cinco dimensóes: uma morfologia humana, uma dinâmica vital, um sistema de diagnose, um sistema terapêutico e uma doutrina médica", embasados em uma sexta, a cosmologia. Portanto, diferentemente do se que pensa, não é apenas a racionalidade biomédica que é detentora de uma racionalidade própria, embora seja esta a racionalidade médica que se tornou hegemônica com o advento do cientificismo no campo da medicina na cultura ocidental, no final do século XIX.

${ }^{2}$ Vale ressaltar que, nas sociedades ocidentais, de um modo geral, tanto o discurso médico-psiquiátrico quanto o discurso psicológico-psicanalítico ocupam lugar privilegiado. Esses discursos substituíram a centralidade do discurso religioso (na modernidade, com o processo denominado "secularização") e 
do discurso político. A psiquiatria e a psicologia atendem, desta maneira, ao sentimento de desamparo vivenciado pelo sujeito moderno e livre, que, a partir do declínio das grandes ideologias religiosas e políticas, viu-se obrigado a se autodestinar. O sujeito individualista, desamparado e angustiado com a própria liberdade, encontra nesses campos do conhecimento as normas sobre o que deve e o que não deve fazer para ser feliz e evitar o sofrimento (ver LUC FERRY, 2006; 2007) sobre a queda das ideologias religiosas, sobretudo com o Iluminismo, e das ideologias políticas. Esta última foi intensificada na Pós-Modernidade ou Modernidade Tardia, tendo como marco simbólico a Queda do Muro de Berlim, em 1989 - ver também Williams e Calnan (1996), sobre o processo de secularização.

${ }^{3}$ Martins (2004), em seu artigo "Filosofia e saúde: métodos genealógico e filosófico-conceitual", propõe que no método filosófico-conceitual, os conceitos devem ser utilizados como ferramentas para a solução de problemas específicos. "Uma metodologia, portanto, filosófico-conceitual consiste na criação e/ou utilização de conceitos que nos permitam propor modos de ver o mundo, ou um problema específico, que o vitalize, de uma maneira outra que a habitual" (MARTINS, 2004, p. 956).

${ }^{4} \mathrm{O}$ objeto de estudo da psiquiatria pode ser definido em um sentido mais abrangente - em oposição à definição reducionista dos manuais diagnósticos vigentes, como o DSM, que reduzem o transtorno mental à doença mental (mental disease) no sentido estritamente médico, sendo as categorias reconhecidas como tipos naturais que existem independentemente das construções linguísticas - como disfunções internas socialmente inapropriadas (HORWITZ, 2002) ou a existência-sofrimento do sujeito em sua relação com o corpo social (ROTELLI, 1990).

${ }^{5}$ A teoria pulsional freudiana pode ser dividida em dois momentos: a primeira formulada em "As pulsóes e suas vicissitudes", de 1915, e a segunda, a do dualismo pulsional, de 1920. No texto de 1915, Freud admite que a conceituação e a classificação das pulsões são ainda, bastante obscuras, e que os conceitos, de uma forma geral, embora devam guardar relação significativa com o material empírico, não devem ser rígidos. Na primeira teoria pulsional, ele distingue duas principais pulsões: sexuais e de autoconservação. Freud ainda atrela as pulsões sádicas ou de domínio - portanto, o elemento agressivo - à pulsão de autoconservação. Na segunda teoria pulsional, as pulsões sexuais e as pulsões de autoconservação são constituintes das pulsões de vida. Como mostra Lima (2007), Freud relutou em considerar as pulsões agressivas como primárias, o que resultou em discordâncias por boa parte dos psicanalistas. A meu ver, parece razoável considerar as pulsões sexuais e agressivas como primárias correlatas aos instintos biológicos sexuais e agressivos - que servem à autoconservação do indivíduo/ espécie. Ambas, quando intrincadas, constituem as pulsões de vida. Por outro lado, na desintrincação, as pulsões agressivas adquirem sua dimensão de destrutividade, que caracteriza as pulsões de morte. 


\section{Abstract}

\section{The traumatic in psychoanalysis and psychiatry: ethical and political implications}

This paper aims to articulate the psychoanalytic and psychiatric discourse on trauma, extracting the ethical and political implications of this link, and promote a rescue of subjectivity by psychiatry. The justification is ethical and pragmatic. The methodology consists of the non-systematic review of the literature, by selecting texts that focus on the traumatic in psychoanalysis - from the Freudian categories "traumatic neurosis", "repetition compulsion", "death drive" and "passage to the act," as well as texts of post-Freudian authors and literature about the testimonies of historical catastrophes, which are located on the order of the traumatic unrepresentative - as well as the selection of texts in the field of psychiatry, which deal with "early stressors" and "posttraumatic stress", emphasizing the relationship between early stressors and the subsequent development of psychopathology. It also emphasizes the individual susceptibility to certain traumatic events, as well as the neurobiological bases of PTSD. Important ethical and policy implications from the joint proposal, that impact within the clinic are extracted, leading to a more effective practice, and socio-political context, with the formulation of public policies on mental health, aimed at preventing trauma generator events as well as the supply of qualified services to patients undergoing traumatic experiences.

Key words: psychic trauma; unrepresentable; early-life stress; post-traumatic stress. 